\title{
Desafios enfrentados por tradutores e intérpretes de libras nas aulas de matemática
}

\author{
Vanessa de Paula Correa* \\ Anderson Roges Teixeira Góes** \\ Heliza Colaço Góes***
}

\section{Resumo}

A educação inclusiva possui como princípio que a escola é direito de todos e que os indivíduos participantes do processo de aprendizagem devem se desenvolver e aprender no mesmo espaço, tendo atendidas suas necessidades especiais. Quanto ao trabalho com estudantes surdos é necessário que a comunidade escolar promova o conhecimento e a integração entre os pares de surdos e ouvintes. Ainda para atender as especificidades do estudante surdo é necessária a participação de mais um sujeito, além do professor e do estudante, o profissional Tradutor e Intérprete de Libras (TILS). Com isso, o presente texto busca identificar as principais dificuldades encontradas pelo TILS, durante a sua atuação em aulas da disciplina de Matemática. Inicialmente, são analisados textos que indicam os direitos de pessoas com deficiências, no viés do estudante surdo, mostrando a legislaçáo que garante a inserção desses estudantes nas classes regulares de ensino, a regulamentação do exercício da profissão do TILS e uma visão a respeito de como o professor, o TILS e o estudante surdo encaram o ensino de matemática na perspectiva inclusiva. $\mathrm{Na}$ sequência, foi aplicado questionário composto de 21 questôes (objetivas e discursivas) a sete TILS, buscando verificar algumas características e dificuldades vivenciadas por esses profissionais. Com base na análise dos dados obtidos, evidencia-se a ausência de sinais específicos para termos matemáticos, acarretando um dos principais obstáculos encontrados nas traduçôes e interpretaçôes nas aulas.

Palavras-chave: Educação inclusiva; Estudantes surdos; Tradutor e intérprete de Libras; Matemática.

\footnotetext{
* Professora graduanda em Matemática pela Universidade Federal do Paraná, Curitiba, Paraná, Brasil.

** Professor doutor em Métodos Numéricos em Engenharia pela Universidade Federal do Paraná, Curitiba, Paraná, Brasil.

*** Professora doutora em Educação pela Universidade Federal do Paraná, Curitiba, Paraná, Brasil.
} 


\title{
Challenges faced by Translators and Interpreters of LIBRAS in Mathematics classes
}

\begin{abstract}
Inclusive education has as a principle that school is the right of all and that the individuals participating in the learning process must develop and learn in the same space, having met their special needs. As for working with deaf students, it is necessary for the school community to promote knowledge and integration between deaf and hearing peers. Also, to work the specifics of the deaf student, it is necessary to have one more subject, besides the teacher and the student, the professional Translator and Interpreters of LIBRAS (TILS). With this, the present text seeks to identify the main difficulties encountered by TILS during their working in classes in the mathematics discipline. Initially, are analyzed texts that indicate the rights of persons with disabilities, on the bias of the deaf student, showing the legislation that ensure the inclusion of these students in the regular classes of education, the regulation of the exercise of the profession of TILS and a vision as to how the teacher, the TILS and the deaf student view the teaching of mathematics in an inclusive perspective. In the sequence was applied a questionnaire composed of 21 questions (objective and discursive) to seven TILS, seeking to verify some characteristics and difficulties experienced by these professionals. Based on the analysis of the data obtained it is evident the absence of specific signs for mathematical terms leading to one of the main obstacles encountered in translations and interpretations in class.
\end{abstract}

Keywords: Inclusive education; Deaf students; Translator and interpreter of Libras; Mathematics.

\section{Introdução}

A comunicação é um fator fundamental para a relação entre seres humanos. A língua representa uma possibilidade de interação social. Por meio dela, o indivíduo não só se comunica, mas também tem acesso à informação. Com isso, uma pessoa pode se comunicar por diversas formas de linguagem: oral, escrita, gráfica, visuoespacial e sensorial. Para as pessoas surdas há uma linguagem específica para se comunicar com qualquer pessoa, chamada no Brasil de Língua Brasileira de Sinais (Libras).

Apesar da Libras ter sua origem em 1857 (SOUZA, 2009), a educação inclusiva para estudantes surdos brasileiros é uma conquista recente, que ocorreu quando eles tiveram seus direitos estabelecidos por meio da legislação. Dentre os direitos garantidos, destaca-se a inclusão dos estudantes surdos na rede regular de ensino com qualidade. Um dos agentes para que isso seja cumprido é o fato de que para auxiliá -los na comunicaçáo e compreensão de conceitos em sala de aula, a partir de 2005, é garantida a presença do profissional Tradutor e Intérprete de Libras (BRASIL, 2005). 
Devido à obrigatoriedade da permanência do TILS no ambiente escolar, surge a formação para esses profissionais em nível de ensino superior, sendo a Universidade Federal de Santa Catarina (UFSC) a pioneira em criar o curso de Letras Libras, impulsionando outras instituiçôes, públicas e privadas, a criar cursos com esse enfoque (DALL'ALBA; SARTURI; SANDERSON; 2014).

A importância do TILS nas salas de aula é indiscutível, pois esse profissional é quem faz com que o estudante tenha acesso aos conteúdos das disciplinas, ministrados em língua portuguesa, por meio da tradução em Libras. É evidente que o TILS, por ter cursado graduação em Letras, não possua formação nas especificidades de cada área do conhecimento da Educação Básica e/ou Ensino Superior. Entáo surgem questionamentos a respeito de como ocorrem às traduçôes nas aulas de Matemática para o estudante surdo, uma vez que a linguagem matemática possui, também, linguagem própria, com estrutura lógica, sendo necessário conhecer o vocabulário específico dessa disciplina. Um TILS, que não possua formação em Matemática, pode vir a traduzir algum conceito, que ficará desprovido de sentido nessa área, o que interfere diretamente no ensino e aprendizado do estudante.

Cabe ressaltar que em Libras existem sinais específicos de matemática, mas o vocabulário na língua portuguesa para a matemática é extenso e se deve também enfatizar que as outras áreas do conhecimento possuem sinais específicos. Assim, esperar de um único profissional o domínio de todos os conteúdos e conceitos escolares, nos mais diversos níveis, é utopia.

Com isso, esta pesquisa busca investigar as dificuldades encontradas pelos TILS durante as aulas de Matemática, com a finalidade de minimizar, ainda que pontualmente, algumas lacunas no processo de ensino-aprendizagem de estudantes surdos. Para isso, foi elaborado um questionário com 21 questóes (objetivas e discursivas), aplicado de forma on-line no segundo semestre de 2016, que contou com a participação de sete TILS, atuantes no ambiente escolar nas aulas de Matemática. As questôes buscam verificar como esses profissionais interpretam as aulas dessa disciplina e as simbologias específicas (mesmo para palavras com significados diferentes quando não pertencente à área de Matemática).

\section{Consideração sobre a educação de estudantees surdos e a educação matemática}

$\mathrm{O}$ atendimento a estudantes surdos teve início no Brasil na época do Império, com a criação do Instituto dos Surdos-Mudos (1857), hoje denominado Instituto Nacional da Educação dos Surdos, no Rio de Janeiro. No entanto, com o Congresso de Miláo (1880) foi anunciada a proibição de língua de sinais em todo o território Brasileiro (FERRARI, 2014). Com essa tentativa de extinguir a língua de sinais, Ferrari (2014) afirma que ficou registrada uma fase na cultura surda, marcada por exclusão e sofrimento, o que mudou radicalmente a história dos surdos. Somente nos anos 1960 foi que se evidenciaram os movimentos das comunidades surdas, para defender seus direitos linguísticos-culturais e conquistar uma educação bilíngue. Por volta dos 
anos 80, iniciou-se no Brasil a atuação de intérpretes em Língua Brasileira de Sinais. A princípio, a atuaçáo desses profissionais ocorreu na educação informal, como em trabalhos religiosos (QUADROS, 2004).

Com a garantia de direitos das pessoas com necessidades especiais, por meio da Declaração de Salamanca (1994), conjuntamente à Linha de Ação sobre Necessidades Educativas Especiais, iniciaram-se as discussóes que findaram em leis para garantir os direitos das pessoas surdas no Brasil principalmente no ambiente escolar.

Diversas são as leis que garantem o direito dos estudantes com necessidades especiais e, dentre eles, os estudantes surdos. Iniciando com a Política Nacional de Educação Especial (BRASIL, 1994), precedida de outras como Lei de Diretrizes e Bases da Educação Brasileira (BRASIL, 1996); Decreto n. 3.298 de dezembro de 1999, regulamentando a Lei n. 7.853/89, que ressalta a ação complementar da educação especial na Educação Básica (BRASIL, 1999); Decreto n. 3.956/2001, ressaltando que pessoas com alguma necessidade especial possuem os mesmos direitos humanos e liberdades fundamentais que as demais pessoas (BRASIL, 2001a); Diretrizes Nacionais para a Educação Especial na Educação Básica (BRASIL, 2001b); Plano Nacional de Educação - PNE, Lei n. 10.172/2001 (BRASIL, 2001c); Lei Federal 10.436/2002, que oficializa a Língua Brasileira de Sinais (BRASIL, 2002a); Resolução CNE/CP n. 1/2002 do Conselho Nacional de Educação - Conselho Pleno que estabelece as Diretrizes Curriculares Nacionais para a Formação de Professores da Educação Básica (BRASIL, 2002b), entre outras.

Pode-se ressaltar que no ambiente escolar a garantia de educação com qualidade é assegurada ao inserir todos os estudantes em mesmas condiçốes de ensino (BRASIL, 2005). O atendimento especializado, a oferta obrigatória do ensino e uso da Libras como língua dominante e o ensino da Língua Portuguesa como segunda língua são direitos importantes para os estudantes surdos. Esse direito é reafirmado em 2010, com a educaçáo em escolas ou classes bilíngues, tendo a presença de Tradutores e Intérpretes de Libras - profissão regulamentada por meio da Lei n. 12.319/10 (BRASIL, 2010). Cabe ressaltar que não é responsabilidade somente dos TILS a comunicação com os estudantes surdos, para que compreendam os conceitos escolares/ científicos, mas o professor regente de cada disciplina deve buscar metodologias sobre como abordar os conceitos com os estudantes e, além disso, comunicar-se em Libras.

A comunicação do professor com o estudante surdo é possível sem o domínio de Libras, porém, é uma comunicação "superficial", nada precisa, tendo interferência direta na aprendizagem do estudante, pois como apontam Miranda e Miranda (2012, p. 39) "não saber Libras pode se tornar uma barreira para o ensino do professor, da mesma maneira que só o seu conhecimento não é suficiente para um processo de ensino-aprendizagem completo".

Surgem também outros desafios quando o professor se depara com um estudante surdo em sala de aula, além da linguagem de comunicação. Esses são questionamentos involuntários: Como se deve trabalhar com aquele estudante? Como enfrentar essa diversidade com relação ao ensino? Minha formação acadêmica/profissional é suficiente para trabalhar com esse tipo de inclusão? Quais são as metodologias adequadas? 
Quanto às aulas de matemática, tema de análise da atuação do TILS nesta pesquisa, as interpretaçôes e traduçôes realizadas podem ser umas das barreiras encontradas nesse processo educacional se não for realizada de forma adequada. No entanto, devido à atuação do TILS, é de suma importância ter o cuidado de não confundir as responsabilidades do professor com esse profissional. Assim, cabe ao professor dispor da metodologia apropriada nesse processo de ensino-aprendizagem.

Muitos estudantes apresentam dificuldades em matemática e elas podem ser justificadas por vários motivos: o conceito pré-formado de que a "matemática é difícil", a metodologia tradicional com ênfase excessiva ao cálculo, o uso inadequado de alguns recursos pedagógicos, a falta de contextualização e a linguagem matemática específica.

Em relação às dificuldades apresentadas por estudantes surdos, além dos itens anteriores, é necessário lembrar que as aulas são ministradas oralmente pelo professor e traduzidas por TILS. Muitos professores se utilizam da entonaçáo da voz como recurso para essa disciplina, procurando chamar a atenção do estudante. Isso dificulta a compreensão do estudante surdo que está incluso em turma com ouvintes. Como afirmam Santos e Souza (2013, p. 8) "a matemática não se trata de uma disciplina com estratégia de fácil entendimento por estudantes surdos, visto que, a oralidade se faz necessária em virtude de participarem de uma turma junto com ouvintes".

A educação inclusiva para surdos é entrelaçada entre três sujeitos: professor, intérprete e estudante surdo. Dessa forma, não cabe a culpa da situação de fracasso, em relaçáo à compreensão de determinados conceitos, a apenas um dos participantes. É necessário que, para uma educação efetiva, os três indivíduos estejam envolvidos na busca de alternativas para a soluçấo dos problemas encontrados. Como Ferrari (2014, p. 113) aponta "Ao longo do desenvolvimento deste estudo, pude perceber que a atuação do intérprete em uma sala regular ainda é obscura para todos os envolvidos: intérpretes, estudantes surdos e professores".

Diante da relação de mediação que o TILS de Libras realiza entre professor e estudante surdo, entre colegas e estudante surdo e principalmente entre a disciplina e o estudante surdo é necessário investigar como essas traduçóes e interpretaçôes são efetuadas, a fim de verificar se elas são realizadas de maneira satisfatória e correta para o entendimento dos estudantes. Dessa forma, procurando evidenciar os desafios dos TILS, em relação à disciplina de Matemática, esta pesquisa aborda alguns fatores, apresentados nesta seçáo e nas anteriores, por meio da metodologia apresentada a seguir.

\section{Metodologia}

Para verificar os objetivos deste trabalho, foi elaborado um questionário com 21 perguntas. Para coleta de dados utilizou-se um formulário on-line, disponibilizado em outubro de 2016. Esse instrumento de coleta de dados possui duas categorias. $\mathrm{Na}$ primeira, procurou-se investigar as qualificaçóes, competências e experiências dos TILS (perguntas de 1 a 9) e na segunda foram verificadas as relaçóes dos TILS com as disciplinas do currículo e, em especial, suas relaçóes com os conteúdos matemáticos (perguntas de 10 a 21). 
O recrutamento de participante para a pesquisa ocorreu por intermédio de profissionais da educação, que possuíam contato com TILS, atuantes na educaçáo formal ou não, de instituiçôes públicas e privadas. Ainda, foi disponibilizado o recrutamento em redes sociais, mas náo houve interessados em participar da pesquisa. Assim, houve a participaçáo de sete TILS, que atuavam em instituiçóes de ensino no referido ano.

As três primeiras perguntas relacionam-se à identificação do entrevistado (nome, idade, sexo). As próximas cinco questóes referem-se à qualificação e experiência profissional (escolaridade, onde aprendeu Libras, tempo de experiência profissional, tipo de instituição que trabalha/trabalhou), a fim de conhecer as qualificaçôes do entrevistado, com a finalidade de identificar se eles possuíam atuaçóes na área de Ciências Exatas. Desse modo, verificando o objetivo de analisar se o domínio da linguagem matemática facilitaria ou não as traduçóes e interpretaçóes das aulas.

As demais perguntas ( 9 a 21) estão relacionadas à relação do tradutor intérprete de Libras com o estudante e o professor de Matemática; principais disciplinas que considera difíceis para a tradução e interpretação; como é considerada a transposição dos conteúdos matemáticos; quais são os principais obstáculos encontrados na tradução e interpretação de conteúdos matemáticos; sugestôes do TILS para minimizar esses "obstáculos".

\section{Análise dos dados coletados}

Como forma de preservar a identificação dos participantes, os sete tradutores intérpretes de Libras, que responderam ao questionário, serão denominados TILS1, TILS2, TILS3, TILS4, TILS5, TILS6 e TILS7. Cabe ressaltar que o baixo número (sete) de participantes mostra como os TILS ainda são pouco conhecidos, pois a gama de profissionais da educação, pois houve uma grande divulgaçáo entre os profissionais da educaçáo, para que indicassem tradutores intérpretes como possíveis entrevistados para esta pesquisa, inclusive nas redes sociais. No entanto, a amostra confirma ou refuta algumas de nossas hipóteses nesta pesquisa.

Os profissionais participantes apresentam em média 6,8 anos de experiência na área, sendo que $85,7 \%$ estão em prática de ofício em escolas públicas e 14,3\% em escolas privadas. Apenas um dos participantes é graduado em Letras/Libras (TILS5); um em Matemática (TILS1) e os outros pós-graduados em diferentes áreas de conhecimento. Isso demonstra que a formação do TILS ainda não é uma prioridade para exercer a profissão, talvez pelo fato de que os primeiros cursos de Letras/Libras tiveram egressos há menos de uma década.

Dos participantes não formados em Letras/Libras, 33\% informaram que aprenderam Libras em instituiçóes religiosas; $17 \%$ aprenderam com os pais; $17 \%$ em disciplinas acadêmicas; $17 \%$ em formação continuada; $16 \%$ não responderam à pergunta. Esses resultados indicam que ainda são poucos os tradutores intérpretes, que aprenderam Libras em disciplina acadêmica $-17 \%$. Isso corrobora com a média de atuação profissional como TILS que é de 6,8 anos, ou seja, está dentro da "janela" de 10 anos da oferta obrigatória da disciplina de Libras, a partir do Decreto 5.626 
de 22 de dezembro de 2005 (BRASIL, 2005), justificando os relatos de os TILS não terem aprendido Libras em algum tipo de instituição de ensino, visto que todos os envolvidos possuem formação acadêmica.

Como acompanham os alunos em todas as aulas/disciplinas é comum, no exercício de sua função, o profissional apresentar dificuldades em determinadas áreas do conhecimento. Das análises realizadas com nossos participantes (pergunta 9), foram investigadas as disciplinas que consideram ter maior dificuldade de traduçáo e interpretação, devido a sinais específicos. As disciplinas citadas foram Biologia (TILS3, TILS4 e TILS5); Física (TILS3, TILS4 e TILS5); Química (TILS3, TILS4 e TILS5); Português (TILS6 e TILS7); Inglês (TILS6). Destaca-se o relato do TILS7: "Cada disciplina tem sua peculiaridade. Sinto mais dificuldade quando tenho que interpretar uma disciplina ou contexto, que náo acompanhei desde o início do desenvolvimento do trabalho". Isso mostra que o trabalho realizado pela tríplice "professor x TILS x aluno” deve ocorrer desde o início do ano letivo. Disso, há a refuta da hipótese de que a Matemática seria a disciplina em que os tradutores e intérpretes de Libras encontrariam maior dificuldade de tradução e interpretação, devido à falta de sinais.

A fim de constatar alguns pontos que interferem nas traduçôes e interpretações realizadas pelos TILS, com relação à linguagem matemática, o que consequentemente afeta no aprendizado do estudante surdo, inicialmente verificou-se como é a relação do TILS com o professor de Matemática e também a relação do TILS com o estudante surdo. Os relatos quanto à relação do TILS e o professor de Matemática indicam que são harmoniosas e favoráveis ao processo de ensino-aprendizagem. No entanto, há necessidade de tempo extraclasse para que TILS e professores conversem sobre os conceitos/conteúdos que seráo abordados na aula.

O TILS6 justifica nossa hipótese quando declara que dificuldades em interpretaçôes e traduçôes seriam minimizadas se os tradutores interpretes possuíssem afinidade/formação em áreas de conhecimento específicas, além de graduação em Letras/LIBRAS. O TILS7 indica que, quando se tem comprometimento entre os profissionais atuantes no processo de ensino-aprendizagem, o objetivo principal, que é o aprendizado do aluno, ocorre de forma efetiva. Esses relatos corroboram com o apontado por Zampieri (2006 apud LACERDA, 2006, p. 73): "Os modos de atuar do professor interferem no modo de atuar do TILS, e essas questóes precisam ser consideradas cuidadosamente para um bom andamento do trabalho escolar".

Quanto à relação entre o TILS e o estudante surdo, observou-se que os sete participantes relatam resultado positivo: "Ótimo sempre" (TILS1); "Eu sempre me dou bem com os estudantes e sempre busco ajudá-los" (TILS2); "Mantenho uma boa relação de respeito com eles" (TILS3); "Boa relação" (TILS4); "Ótima, são meus clientes e muitas vezes amigos" (TILS5); "Excelente" (TILS6); relaçáo "de amizade" (TILS7). Cabe ressaltar que o TILS5 atua em sala de aula e nas áreas jurídica e médica.

O relacionamento positivo entre TILS e estudante surdo é considerado bastante importante para o ensino e aprendizado. Se ele não for bom, pode ser criada uma barreira na aprendizagem do estudante, dificultando ou até mesmo impedindo a compreensão do conteúdo. 
No que se refere à constatação da busca de novas metodologias da parte do professor de Matemática para ajudar os estudantes surdos, três participantes mencionaram não haver essa mobilização da parte do professor, assim observado: "Não vejo, como comentei infelizmente a maioria dos professores não estão preparados para atendê-los e acham que isso é papel do intérprete" (TILS2); "Não, o professor dá a mesma aula" (TILS4); "Não, nunca." (TILS5). Um dos TILS participante constata pouca busca por metodologia específica para ensinar o estudante surdo. As respostas dos demais tradutores intérpretes não passaram pela análise, pois elas se encontraram fora de contexto da pergunta.

Os relatos anteriores apresentam a acomodação do professor, que busca não sair de sua zona de conforto, transferindo sua responsabilidade aos TILS, sem se envolverem de maneira efetiva com a educação do estudante surdo, sobretudo, integrando recursos visuais, visto que a maioria desses estudantes possui domínio de uma língua espaço-visual. Pode-se afirmar também, que a inclusão do estudante surdo não se faz de maneira efetiva, pois há a necessidade de os professores compreenderem quais são os papéis de cada participante nesse processo.

Quanto às dificuldades do tradutor intérprete de Libras frente à disciplina de Matemática (pergunta 14), o resultado encontrado não deixou claro como a tradução é vista pelos TILS de maneira geral, ou seja, se é fácil ou difícil, uma vez que dois deles disseram que é fácil e a mesma quantidade relata dificuldade. À resposta de um TILS interpretamos como "depende de alguns fatores" e outros dois entrevistados não apresentaram repostas conclusivas.

Uma justificativa apresentada pelos que concordaram em ser fácil a tradução e interpretação das aulas de Matemática está baseada no fato de a disciplina ser bastante visual. Aqui não há maiores detalhes do trabalho realizado pelo professor regente, se ele utiliza recursos visuais ou o TILS referiu-se a conteúdos que podem tornar alguns níveis da matemática mais visuais, como o ensino da Geometria, ou metodologia de professores "mais algébricos", que aplicam algoritmos e exercício semelhante a "façam como o modelo".

A justificativa do TILS em que interpretamos como "depender de outros fatores" é "em alguns conteúdos são fáceis, em outros não, porém tudo depende da didática do professor, de sua postura, que são fatores que influenciam na interpretação" (TILS5). Ou seja, percebe-se que a metodologia do professor influencia no grau de dificuldade ou facilidade de tradução e interpretaçáo por parte do tradutor intérprete de Libras.

O TILS6 relatou não ser fácil a tradução e interpretação, justificando sua resposta da seguinte maneira: "É preciso trabalhar o tempo todo com adaptação de sinais para terminologias não conhecidas". Quanto à falta de sinais para traduçáo e interpretação de alguma terminologia matemática e explicitação de alguns desses sinais, o TILS3 não se recordou de ter havido algum episódio. No entanto, os demais TILS relataram já terem se deparado com a falta de algum sinal, mas somente dois relatam que combinaram com os estudantes de criarem uma representação para tal 
palavra/conceito matemático. O TILS3 relata "peço para o professor mostrar através de imagens ou escrever", evidenciando o trabalho conjunto que deve ser realizado com o professor regente, mostrando a responsabilidade de ambos no processo de ensino-aprendizado.

Em complemento, nessa pergunta foi solicitado que explicitassem quais conteúdos matemáticos possui maior frequente de ausência de sinais específicos. De maneira geral, as respostas obtidas indicam as áreas de estatística, probabilidade e trigonometria, de modo particular, para o TILS1 os conceitos de nível superior (Ensino Superior) são os que mais apresentam ausência de sinais específicos.

Dos participantes da pesquisa, $86 \%$ percebem que a tradução literal de algumas palavras no contexto matemático ocasiona a falta de sentido para a sentença matemática. Com isso, verifica-se que os TILS reconhecem suas limitaçôes nessa área de conhecimento e que há a necessidade de conhecer previamente o contexto em que estáo sendo realizadas as traduçóes. Isso corrobora com a afirmaçáo do TILS5, quando afirmou em uma das perguntas que a relaçáo com o professor de Matemática é boa, mas não há disponibilidade prévia de conversar sobre os conteúdos.

Em uma das perguntas foram apresentadas três sentenças matemáticas com palavras destacadas (razão, constante e corda) para que os TILS interpretassem esses sentidos e indicassem o conhecimento de sinais específicos, as respostas foram avaliadas sem rigor matemático, ou seja, foram consideradas corretas todas as que se aproximaram do significado real das palavras na matemática.

Para as três palavras citadas, o TILS2 respondeu "utilizo classificador ou explico o que é, e peço para o professor mostrar a imagem ou escrever. O surdo é visual e também tem o glossário de matemática: http://calculibras.wixsite.com/home/glossario".

Sabendo que o significado de "razão" na matemática é a relação entre dois números de mesma grandeza, dois TILS apresentaram respostas coerentes dentro do significado matemático: "relação de números" (TILS5) e "razão possui mesmo significado de divisão" (TILS6). O TILS3 omitiu a resposta e os outros três tradutores intérpretes apresentaram respostas em que não foi possível a interpretação, como no caso do TILS-7 que justificou o significado de razão relatando que "Na matemática são muitos exemplos, a repetiçáo de cálculos leva a entender como faz. Demonstração de exercícios seguidos de exemplos”.

Em relação à palavra "constante", que na matemática significa "valor fixo", quatro das respostas foram coerentes ou parcialmente coerentes com o contexto envolvido. Dentre o relatado temos "sempre igual" (TILS1 e TILS2); "valores contínuos" (TILS6); "algo que sempre vai acontecer" (TILS7).

Para o significado de "corda", que na matemática significa o segmento de reta cujas extremidades são dois pontos distintos de uma circunferência, não houve nenhuma resposta correta. Alguns confundiram o significado de "corda" com "material para aproximar mais do concreto" (TILS7), referindo-se a material utilizado para 
amarrar objetos ou usado em atividades esportivas. Outros descrevem algo que não é possível analisar, com "espessura arredondada" (TILS6). As respostas obtidas nessa pergunta vêm ao encontro dos resultados apresentados Ferrari (2014). A autora percebe em sua pesquisa que traduçóes de determinadas palavras são realizadas fora do contexto matemático. Ainda podemos reafirmar que a falta de formação específica dos TILS em outras áreas do conhecimento influencia no processo de ensino-aprendizagem do estudante surdo.

A opinião dos TILS em relação aos estudantes surdos apresentarem mais dificuldades em matemática do que estudantes ouvintes foi bastante divergente. Para os que acreditam que os surdos apresentam mais dificuldades quando comparados com os estudantes ouvintes perpassa desde a formação nos anos iniciais do ensino fundamental, pela família e a falta de apoio pedagógico em contraturno (TILS1 e TILS4). O TILS5 afirma que em relação à matemática os estudantes surdos possuem ótimo desempenho. Os demais náo associam a dificuldade na disciplina ao fato do estudante ser surdo.

Os tópicos matemáticos percebidos pelos TILS em que os estudantes surdos apresentam mais dificuldades de compreensão são equaçóes, expressões numéricas, razão, função afim, raiz quadrada, potência, relação de maior ou menor e situação problema de maneira geral. Alguns desses resultados confirmam conteúdos apresentados na pesquisa de Souza (2009), mostrando percentual elevado de estudantes surdos $(91 \%)$ que relataram ter alguns tipos de dificuldade em aprender matemática. A autora levanta dados referentes a quais conteúdos matemáticos, presentes na grade curricular do $5^{\mathrm{a}}$ e $6^{\mathrm{a}}$ série, atualmente $6^{\mathrm{o}}$ e $7^{\mathrm{o}}$ ano, do Ensino Fundamental os estudantes apresentavam maiores dificuldades. Dentre os resultados, os quatro conteúdos de maior percentual são: radiciação; elemento fracionário; porcentagem e equação. Em contrapartida, os conteúdos com menores percentuais são os de geometria, média, operaçôes básicas e máximo divisor comum.

Para finalizar o questionário foi solicitado aos TILS que sugerissem algumas soluçóes para minimizar possíveis traduçóes "fora de contexto" com relação à linguagem matemática e suas especificidades. Dentre o apontado pelos TILS selecionamos:

- Livro didático adaptado em forma de vídeos (formato DVD), sendo adotado em todas as escolas (TILS1);

- Materiais adaptados, coloridos e bem visuais, jogos e materiais concretos (TILS6 e TILS7);

- Realização de mais congressos sobre esse tema, discutindo os diferentes conteúdos e criação de um glossário específico (TILS5);

- Tentar ao máximo que os TILS entendam a matéria e que ambos, estudante surdo e TIL, pratiquem muito a matemática (TILS4);

- Mais estudos específicos na área de tradução nesse contexto (TILS1 e TILS3); 
- O professor buscar novos métodos para o ensino e aprendizado do estudante surdo e aprender Libras, com a finalidade de se relacionar diretamente com o estudante surdo (TILS2).

Com a análise dessa pergunta, percebe-se a escassez de materiais adaptados a estudantes surdos e, também, a falta de formação do professor de Matemática para o trabalho na educação inclusiva. Com isso, podemos questionar se a inclusão está realmente sendo efetivada em sala de aula ou os estudantes estão simplesmente sendo inseridos em salas "regulares" com a finalidade de apenas cumprir uma lei ou se as mantenedoras do sistema educacional estão se preocupando com processo de ensino -aprendizagem desses estudantes.

\section{Considerações finais}

A inclusão escolar é um direito de todos, sendo respaldado pela Constituição Federal. Dessa forma, cabe a todos os sujeitos envolvidos nesse processo educacional, escola, professores, TILS, estudantes ouvintes e estudante surdo e familiares fazerem valer seus direitos e seus deveres.

Levando em consideração a tríade "professor x TILS x estudante surdo" podese afirmar que ainda não se faz totalmente clara suas relaçóes dentro desse processo de ensino-aprendizagem, todos precisam de orientação e embasamento, para que possam entender e se aproximar do processo. Esse fato parece não estar muito claro principalmente para o professor, pois com os relatos dos TILS é evidente que muitos docentes não procuram novas metodologias ou recursos para a aprendizagem de estudantes inclusos. Ainda é necessária uma padronização de sinais para determinados termos/definiçôes dentro de conteúdos matemáticos, visto que esses estudantes podem ter alguma mobilidade e os sinais serem diferentes em outras instituiçóes de ensino.

$\mathrm{O}$ fato dos tradutores intérpretes de Libras não terem formação específica em Matemática levam a algumas interpretaçóes e traduçóes errôneas, acarretando negativamente no aprendizado dos estudantes. Por isso é necessário o contato prévio com os conteúdos, com objetivo de entender e esclarecer possíveis dúvidas por parte do TILS.

Outro fator que prevemos como amenizador dessas dificuldades deve ocorrer nos próximos anos, uma vez que os atuais egressos de cursos de licenciatura possuem como disciplina obrigatória em seus currículos a Libras, assim poderão auxiliar os TILS para uma comunicação concisa com os estudantes.

Constatou-se, com os resultados desta pesquisa, a refuta da hipótese de que a Matemática seria a disciplina em que os TILS encontrariam maior dificuldade de tradução e interpretação, devido à falta de sinais. No entanto, dentre as disciplinas citadas, três são da área de exatas, podendo ser investigada se elas foram assim classificadas por alguma relaçáo com a interpretação matemática, utilizada por essas áreas de conhecimento. 
Percebe-se também que existe falta de materiais adaptados para os alunos surdos, os quais náo serviram somente para eles, mas para todos os estudantes, como vídeos e materiais visuais (cartazes, pranchas coloridas, sólidos geométricos). Cabe ressaltar que muitos estudantes ouvintes possuem maior facilidade de compreensão pelo visual do que pela oralidade (GARDNER, 1995).

Todos precisam assumir seus verdadeiros papéis no processo de ensino e aprendizagem, desde a família à mantenedora, passando pela tríade "professor x TILS x estudante surdo", que deve ter uma relação de cumplicidade direta e clara, com o mesmo objetivo de buscar alternativas para que assim se conquiste uma educaçáo de qualidade para o estudante surdo incluso.

\section{Referências}

BRASIL. Conselho Nacional de Educação. Conselho Pleno. Resoluçáo CNE/CEB n. 2, de 11 de setembro de 2001. Institui Diretrizes Nacionais para a Educação Especial na Educação Básica. Brasília: CNE/CEB, 2001 b.

BRASIL. Decreto no 3.298, de 20 de dezembro de 1999. Regulamenta a Lei $n^{\circ} 7.853$, de 24 de outubro de 1989, dispóe sobre a Política Nacional para a Integraçáo da Pessoa Portadora de Deficiência, consolida as normas de proteção, e dá outras providências. Diário Oficial da República Federativa do Brasil, Brasília, 21 dez. 1999

BRASIL. Decreto no 3.956, de 8 de outubro de 2001. Promulga a Convençáo Interamericana para a Eliminaçáo de Todas as Formas de Discriminação contra as Pessoas Portadoras de Deficiência. Diário Oficial da União, Brasília, 9 out. 2001a.

BRASIL. Decreto no 5.626, de 22 de dezembro de 2005. Regulamenta a Lei no 10.436, de 24 de abril de 2002, que dispóe sobre a Língua Brasileira de Sinais - Libras, e o art. 18 da Lei no 10.098, de 19 de dezembro de 2000. Diário Oficial da União, Brasília, 23 dez. 2005.

BRASIL. Lei de Diretrizes e Bases. Lei no 9.394/96, de 20 de dezembro de 1996. Estabelece as diretrizes e bases da educação nacional. Diário Oficial da Uniấo, Brasília, 23 dez. 1996.

BRASIL. Lei no 10.172/2001 de 9 de janeiro de 2001. Aprova o Plano Nacional de Educação e dá outras providências. Diário Oficial da Uniáo, Brasília, 10 jan. 2001c.

BRASIL. Lei no 10.436 de 24 de abril de 2002. Dispóe sobre a Língua Brasileira de Sinais - Libras e dá outras providências. Diário Oficial da União, Brasília, 25 abr. 2002a.

BRASIL. Lei no 12.319 , de $1^{\circ}$ de setembro de 2010. Regulamenta a profissáo de Tradutor e Intérprete da Língua Brasileira de Sinais - Libras. Diário Oficial da Uniâo, Brasília, 2 set. 2010.

BRASIL. Ministério da Educação. Conselho Nacional de Educação. Conselho Pleno. Resoluçáo CNE/CP no 1, de 18 de fevereiro de 2002. Institui Diretrizes Curriculares Nacionais para a Formaçáo de Professores da Educação Básica, em nível superior, curso de licenciatura, de graduaçáo plena. Brasília, 2002b.

BRASIL. Ministério da Educação. Política Nacional de Educação Especial. Brasília, DF: MEC/SEESP, 1994.

DALLALBA, Clarissa; SARTURI, Claudia de Arruda; SANDERSON, Helenne. Curso superior de Letras/ Libras: pioneiro da América Latina. In: IV CONGRESSO BRASILEIRO DE EDUCAÇÂO ESPECIAL E IX ENCONTRO NACIONAL DOS PESQUISADORES DA EDUCAÇÃO ESPECIAL, 2014, São Carlos. Anais do Congresso Brasileiro de Educaçáo Especial, 2014.

FERRARI, Ana Carolina Machado. Atuaçáo do tradutor intérprete de libras na aprendizagem matemática de surdos no ensino fundamental. Dissertação (Programa de Pós-Graduação em Educação: Conhecimento e Inclusão Social) Universidade Federal de Minas Gerais, Belo Horizonte, 2014.

GARDNER, Howard. Inteligências múltiplas: a teoria na prática. Porto Alegre: Artes Médicas, 1995.

LACERDA, Cristina Broglia Feitosa de. A inclusão escolar de alunos surdos: o que dizem estudantes, professores e intérpretes sobre esta experiência. Cadernos Cedes, Campinas, v. 26, n. 69, p. 163-184, maio/ago. 2006.

MIRANDA, Crispim Joaquim de Almeida; MIRANDA, Tatiana Lopes de. O Ensino de matemática para alunos surdos: quais os desafios que o professor enfrenta? Revemat: Revista Eletrônica de Educaçáo Matemática, Santa Catarina, v. 6, n. 1, p. 31-46, 2012. 
QUADROS, Ronice Müller de. O tradutor e intérprete de língua brasileira de sinais e língua portuguesa. Secretaria de Educação Especial; Programa Nacional de Apoio à Educação de Surdos. Brasília: MEC-SEESP, 2004.

SANTOS, Carla Eliza; SOUZA, Clovis Batista de. Matemática para estudantes surdos: uma proposta para intervenção em sala de aula. In: I SEMANA DA MATEMÁTICA DA UTFPR, Toledo/Pr, 2013.

SOUZA, Maria Clara de Melo Magalhāes. Dificuldades no ensino da matemática para surdos. Trabalho de Conclusão de Curso (Graduação em Matemática). Universidade Católica de Brasília, 2009.

\section{Correspondência}

Vanessa de Paula Correa - Universidade Federal do Paraná. Rua XV de Novembro, 1299 - Centro. CEP: 80060-000. Curitiba, Paraná, Brasil.

E-mail: nesinhacorrea@hotmail.com - artgoes@ufpr.b - heliza.goes@ifpr.edu.br

Correspondência em 05 de abril de 2017

Final em 6 de setembro de 2017 
